Revista Tecné, Episteme y Didaxis: TED. Año 2014, Número Extraordinario. ISSN Impreso: 0121-3814, ISSN web: 2323-0126 Memorias, Sexto Congreso Internacional sobre Formación de Profesores de Ciencias. 08 al 10 de octubre de 2014, Bogotá

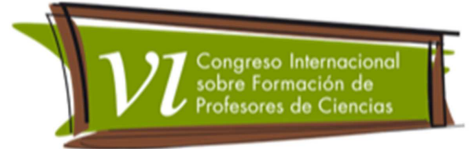

\title{
Formação Continuada de Professores: A Experiência de uma Temática Sociocientífica na Perspectiva do Agir Comunicativo
}

Bortoletto, Adriana'; Pacheco de Carvalho, Washington²

Categoria 1. Reflexões e experiências de inovação na sala de aula.

\section{Resumo}

Neste trabalho, apresentamos e discutimos algumas evidências relativas à constituição e evolução de um grupo de estudo, cujos integrantes são professores da rede pública de ensino e dois representantes da universidade. A questão de pesquisa que norteou o trabalho foi: Dentro de contextos comunicativos no ambiente escolar, como são discutidas as questões sociocientíficas por professores em seus processos de formação em exercício? Os dados foram constituídos por meio de gravações em áudio das 21 reuniões realizadas ao longo dos anos de 2011 e 2012. Os dados aqui apresentados e discutidos evidenciaram que a proposta desenvolvida permitiu que os professores identificassem inerentes ao desenvolvimento de uma dialogicidade em sala de aula, assim como, a insuficiência da formação pedagógica e necessidade de desenvolvimento de uma ética discursiva entre os professores.

Palavras-chave: Formação de Professores, Questões Sociocientíficas, Ação Comunicativa.

\section{Introdução}

Há uma dificuldade de valorização de práticas argumentativas no contexto de sala de aula da mesma forma que ocorre no diálogo entre os professores nos horários destinados para a formação e planejamentos de ações pedagógicas. Na dimensão da sala de aula, Giroux (1997) afirma que, não há uma ênfase nos alunos para lerem o mundo criticamente. $O$ que ocorre é apenas o desenvolvimento de habilidades de leitura de forma mecânica, a qual impede a produção de sentido e significado sobre aquilo que é dado como factual.

\footnotetext{
1 Faculdade de Engenharia de llha Solteira - Departamento de Física e Química Universidade Estadual Paulista (UNESP) - e-mail: adribortto@dfa.feis.unesp.br

2 Faculdade de Engenharia de llha Solteira - Departamento de Física e Química Universidade Estadual Paulista (UNESP) - e-mail: washcar@dfq.feis.unesp.br
} 
Revista Tecné, Episteme y Didaxis: TED. Año 2014, Número Extraordinario. ISSN Impreso: 0121-3814, ISSN web: 2323-0126 Memorias, Sexto Congreso Internacional sobre Formación de Profesores de Ciencias. 08 al 10 de octubre de 2014, Bogotá

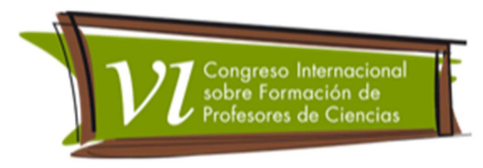

A ausência de um espaço amplo comunicação no ambiente escolar dificulta o processo de formação entre professores, como nas relações aluno-professor e aluno-aluno. É no processo comunicativo, livre de coerções, com o exercício efetivo da argumentação, que as pessoas se entendem, entendem as coisas do mundo e promovem mudanças no status quo.

Neste artigo, buscarmos discutir que para o desenvolvimento da formação científica escolar de alunos, é imprescindivel a formação dos professores de ciências frente aos mesmos objetivos, os quais estão relacionados com: a) o desenvolvimento da prática discursiva (argumentação e entendimento); b) compreensão da natureza da ciência como conhecimento historicamente construído e não linear; c) a dimensão ética e moral da Ciência e Tecnologia; d) compreensão dos conceitos científicos para uma maior leitura do mundo.

Diante disto, enfocamos neste trabalho elementos que envolvem a prática discursiva docente e as questões sociocientíficas como forma de investigar o desenvolvimento e compreensão dos professores quantos a dimensão ética, moral e cultural da natureza da ciência na sociedade contemporânea. Apresentamos a Teoria do Agir Comunicativo de Jurgen Habermas como aporte teórico para a compreensão da prática discursiva docente e da identificação das possiveis relações que os professores podem estabelecer os saberes teórico-pedagógicos das questões sociocientíficas.

\section{Sobre a Ideia de Contextos Comunicativos na Perspectiva Habermasiana}

A linguagem possui papel fundamental na construção do conhecimento e na compreensão do mundo. Segundo Mühl (2003), a linguagem é uma ação humana, faz parte da prática social, ação do sujeito no mundo como mediadora das trocas intersubjetivas entres os atores sociais (Habermas, 2004).

A concepção habermasiana da linguagem leva em consideração a fala argumentativa de diversos participantes que rompem com os pontos de vista subjetivos no intuito de contribuir para a continuidade do conhecimento humano (Habermasa, 2012; Habermas, 2004).

O contexto comunicativo na perspectiva habermasiana é orientado pelas pretensões de validade. Se considerarmos uma situação em que um falante lança uma proposta sobre algum fato ou evento, as pretensões de validade deverão ser consideradas. Essa base normativa é construída ao longo do desenvolvimento do Homem. Assim, o ato de fala deverá satisfazer três pretensões de validade: ser considerada verdadeira pelos participantes, ser considerada sincera uma vez que 
Revista Tecné, Episteme y Didaxis: TED. Año 2014, Número Extraordinario. ISSN Impreso: 0121-3814, ISSN web: 2323-0126 Memorias, Sexto Congreso Internacional sobre Formación de Profesores de Ciencias. 08 al 10 de octubre de 2014, Bogotá

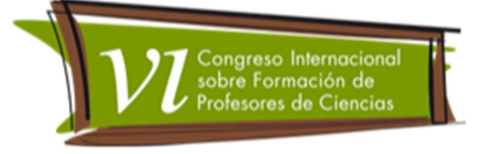

expressa a intenção do falante e ser considerada acertada, pois está relacionada com aspectos éticos e morais reconhecidos pelos participantes que fazem parte do contexto comunicativo (HABERMAS, 2002). Neste contexto, Habermas (2002) entende por "competência comunicativa" a capacidade de o falante orientar a própria fala para o entendimento durante um contexto comunicativo com diversos participantes.

Habermas concebe que a nossa sociedade é composta por duas dimensões, sendo a primeira o mundo da vida e a segunda o sistema. O mundo da vida é o contexto no qual estão inseridas as tradições culturais, as interações sociais e os saberes constituídos ao longo da evolução social. É o local em que os atores sociais podem agir comunicativamente, por meio da crítica, a cerca dos saberes que possam estar em tematização isso porque o mundo da vida é regulado pela linguagem. O sistema é composto pelo Estado e o Capitalismo, os quais são regulados pelo dinheiro e poder.

No entanto, os atos de fala são orientados em função do mundo que fazem menção. Esses mundos (domínios da realidade) são denominados de mundos objetivo, social e subjetivo.

\section{As Questões Sociocientíficas}

Sabemos que as disciplinas científicas possuem um papel importante na compreensão da natureza científico-tecnológica. $O$ ensino de ciências precisa estar coerente com o desenvolvimento crítico dos alunos, com o exercício do pensamento analítico-reflexivo e com o desenvolvimento da capacidade argumentativa.

De uma maneira geral, defendem a necessidade dos alunos compreenderem que as disciplinas científicas escolares são fulcrais para o entendimento da evolução da ciência e tecnologia, inclusive, para o entendimento das problemáticas advindas da interface ciência e sociedade. Estas problemáticas são definidas, no âmbito do ensino de ciências, como questões sociocientíficas. Possuem como características os seguintes pontos: são conhecimentos científicos de fronteira, envolve a interface ciência e sociedade, assim como, as dimensões éticas e morais e, por fim, a formação de opinião (Ratcliffe e Grace, 2003).

O domínio das questões sociocientíficas possui uma estrutura pedagógica que permite o desenvolvimento dos alunos quanto às questões morais e científicas por meio de processos discursivos e interativos no contexto de sala de aula Zeidler et al (2005); Kolsto et al (2006); Rudsberg et al (2013). 
Revista Tecné, Episteme y Didaxis: TED. Año 2014, Número Extraordinario. ISSN Impreso: 0121-3814, ISSN web: 2323-0126 Memorias, Sexto Congreso Internacional sobre Formación de Profesores de Ciencias. 08 al 10 de octubre de 2014, Bogotá

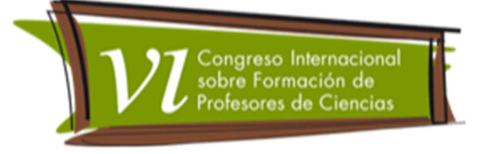

Se de fato, o objetivo do ensino de ciências é potencializar a formação de cidadãos críticos, aptos para analisar as incoerências da sociedade contemporânea e o impacto da ciência e tecnologia no mundo da vida, é imprescindível investigar como ocorre a prática comunicativa no ambiente escolar. Logo, o entendimento de como os professores compreendem de uma questão sociocientífica e a relação com a prática de ensino.

\section{Metodologia}

Esta pesquisa se caracteriza como de gênero qualitativo. Pois compreendemos que - contexto a ser investigado faz parte de uma realidade social construída intersubjetivamente (Alves-Mazzotti e Gewandsznajder, 2002).

O grupo é formado por nove professores de diversas disciplinas (matemática, física, química, filosofia e ciências) e mais dois representantes da universidade a pesquisadora e um graduando em licenciatura em Física.

De comum acordo, as reuniões seriam realizadas semanalmente aos sábados, com duração de três horas por encontro. Nestes encontros seriam discutidos textos sobre formação de professores e questões sociocientíficas, com realizações de seminários pelos próprios professores, como também, discussões coletivas em grupo dos respectivos textos. Ao total foram realizadas vinte e uma reuniões os dados foram constituídos por gravação em aúdio.

\section{Resultados e Discussões}

Neste momento, iremos apresentar e discutir duas evidências que apontam a importância das QSCs para critica da prática de ensino e a ação discursiva dos professores em relação aos pressupostos da ação comunicativa.

No início dos encontros o discurso dos professores era permeado por denúncias, como por exemplo:, a ausência de legitimação do professor perante o Estado, distanciamento da relação professor-aluno e dificuldades de transformações pedagógicas a nível individual como coletivo no contexto escolar.

No episódio (01), IGI relata as cobranças e opressões que o professor da rede pública sofre em função do planejamento administrativo, as quais caracterizam a invasão do sistema no mundo da vida. Conforme Mühl (2003) a escola se torna uma entidade a mercê da tecnocracia e preocupada a atender os imperativos e demandas sistêmicas. 
Revista Tecné, Episteme y Didaxis: TED. Año 2014, Número Extraordinario. ISSN Impreso: 0121-3814, ISSN web: 2323-0126 Memorias, Sexto Congreso Internacional sobre Formación de Profesores de Ciencias. 08 al 10 de octubre de 2014, Bogotá

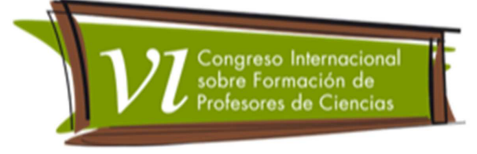

Episódio (01) - IGl: (...) Parece que a escola entra de uma forma perpendicular, não de uma forma direta. Parece, então, que existe um problema, acho que é um conflito de objetivos, do educando, o aluno e o educador. O educador da sua maneira (...) ele tenta fazer o melhor. Mas ele entra em choque com as práticas e a realidade.

IGl: São perspectivas diferentes! Se o Estado está na linha de montagem não vai dar certo! Então nesta linha de montagem do jeito que está impregnado o sistema não vai virar nada! (...)

O reconhecimento das invasões pelos professores é fulcral no nosso entendimento. Pois, por meio destas identificações, a teoria se torna importante e fundamental para o entendimento da ordem social vigente e superação dos obstáculos.

Outro ponto importante constatado na pesquisa é a existência de um ambiente comunicativo escolar. Porém, a características desse ambiente possui tensões e obstáculos que o distanciam da ideia de um espaço público de formação via ação comunicativa. Conforme se pode observar no episódio (02):

Episódio (02) - PA: Mas o problema é o seguinte: para você avaliar e identificar os problemas! Agora tá faltando às ações que precisam ser implementadas para sanar o problema é que elas não acontecem de maneiras satisfatórias. Porque a realidade acaba jogando essa responsabilidade para o professor! (...) Nossa! O que fazer?

POLl: Eu não sei! O que o PA falou! Se todas essas angústias, aí! Ele comenta alguma coisa sobre os muitos objetivos a serem atingidos pelos professores! São muitos objetivos!

POLl: (...) A gente lida com isso todo dia, dá para pensar tudo isso todo dia?

PROF(?): O aluno não tem compromisso e a escola tem obrigação de dar conta! Quando não é computador, é celular, televisão, o aluno vive momentos! Ele deleta! Não tem um compromisso fechado!

As falas dos professores relatam o predomínio da racionalidade sistêmica na escola. Esta presença dificulta o desenvolvimento de um ambiente formativo. $O$ fato de POLI no episódio (02) não ter se preocupado em compreender o ato de fala de PA caracteriza-se como uma quebra da pretensão de validez de acerto que regulam a comunicação ética e moral voltada para o entendimento coletivo dos problemas da escola.

O Potencial das Questões Sociocientíficas como Elemento Problematizador da Própria Prática: 
Revista Tecné, Episteme y Didaxis: TED. Año 2014, Número Extraordinario. ISSN Impreso: 0121-3814, ISSN web: 2323-0126 Memorias, Sexto Congreso Internacional sobre Formación de Profesores de Ciencias. 08 al 10 de octubre de 2014, Bogotá

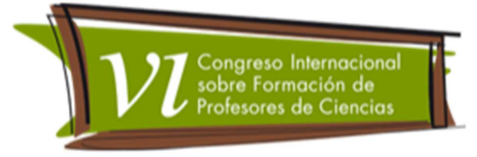

Diante destes pressupostos, o estudo coletivo do referencial teórico sobre (QSC) possibilitou que houvesse uma problematização da prática de ensino do professor em sala de aula, como por exemplo, as tradições culturais dos alunos, a postura do professor em sala de aula, a prática discursiva do professor, a estrutura de organização da aula de forma que o aluno tenha mais espaço para participação discursiva. $O$ episódio abaixo relata a discussão sobre a argumentação em sala de aula:

Episódio (03) - EDR: (...) a argumentação do professor é mínima! Durante a aula cada aluno vem com aquele conhecimento de vida! (...)Ele vem com uma concepção de tal assunto, mas quando entra no conceito científico ele não consegue interagir e relacionar um fator com o outro! (...)

FLA: (....) A forma, a maneira de abordar o texto em sala de aula, o ano passado eu já pré-definia os conceitos! Antes mesmo de pegar os conhecimentos prévios dos alunos e esse ano eu já melhorei nisso!

ADR: Com era antes?

FLA: Por exemplo, dentro da unidade de atomicidade (...). Antes, eu já jogava a teoria assim, e já fui passando todas elas assim, Dalton, Thompson, eu ia jogando tudo! Definindo já! Agora não, eu não consegui definir com eles!

ADR: Como você se sente com esses questionamentos?

FLA: São turmas diferentes! Mas, mesmo assim a participação deles aumenta! Isso que é legal! O questionamento aumenta! Uma maior interação em sala de aula!

Nessas ações os professores EDR, FLA e ADR se reportam aos mundos objetivo, social e subjetivo quando conta as suas experiências em sala de aula com a argumentação (subjetivo), ao relatarem o conteúdo de modelos atômicos ( Objetivo) e por fim o interesse em socializar com todos os participantes do grupo, inclusive, respondendo aos questionamentos de ADR.

\section{Considerações Finais}

O trabalho com as questões sociocientíficas permitiu que os professores identificassem várias dificuldades da prática de ensino presentes no cotidiano escolar. Pelos atos de falas dos docentes é possivel perceber que eles reconhecem a importância da cultura do aluno, da argumentação. Porém, possuem ainda uma concepção naturalizada e insuficiência quanto ao conhecimento pedagógico do conteúdo.

Em relação a ação comunicativa os professores estavam interessados na leitura do referencial teórico das QSCs e faziam menção aos conteúdos específicos. Isso evidencia alusão ao mundo objetivo. 
Revista Tecné, Episteme y Didaxis: TED. Año 2014, Número Extraordinario. ISSN Impreso: 0121-3814, ISSN web: 2323-0126 Memorias, Sexto Congreso Internacional sobre Formación de Profesores de Ciencias. 08 al 10 de octubre de 2014, Bogotá

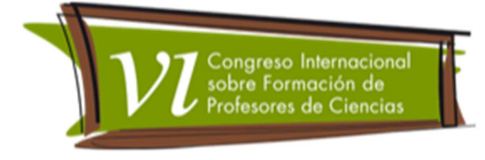

Quanto ao mundo social, alguns docentes tinham dificuldade de enfrentar as apresentações de seminários, em articular o conhecimento teórico disciplinar com os outros participantes do pequeno grupo de pesquisa. Muitas vezes ficavam centrados apenas no mundo subjetivo. Quando a predomínio do discurso centrado apenas em um ou dois mundos existe a ruptura da ação comunicativa voltada para o entendimento do que se fala o que acaba dificultando ações democráticas e participativas no interior da escola.

\section{Referências Bibliográficas}

Alves-Mazzotti, A. J., \& Gewandsznajder, F. (2002) O Método nas Ciências Naturais e Sociais: Pesquisa Qualitativa e Quantitativa. São Paulo. Pioneira.

Giroux, H. (1997) Os professores como intelectuais: rumo a uma pedagogia crítica da aprendizagem. Tradução Daniel Bueno. Porto Alegre: Artmed.

Habermas, J. (2002) Racionalidade e Comunicação. Lisboa: Edições 70.

Habermas, J. (2004) A ética da discussão e a questão da verdade. São Paulo: Martins Fontes.

Habermas, J. (2012 a) Teoria da Ação Comunicativa I. São Paulo. Martins Fontes.

Kolsto, D.S.; Bungun, B.; Arnesen, E.; Isnes, A.; Kristensen, T.; Mathieassen, K. Mestad, I.; Quales, A.; Tonning, V.S.A.; Ulvik, M., (2006) Science Student's Critical Examination of Scientific Information Related to Sociocientific Issues. Science Education. 90 (4), 632-655.

Mühl, E (2003). J. Habermas: ação pedagógica como agir comunicativo. Passo Fundo: UPF.

Ratcliffe M., \& Grace M. (2003) Science education for citizenship: teaching socioscientific issues. Maidenhead: Open University Press.

Rudsberg, K., Öhman, J., Östman, L. (2013) Analyzing Student’s Learning in Classroom Discussions about Sociocientific Issues. Science Education. 97 (4), 594 - 620.

Zeidler, D., Sadler, T., Simmons, L.,M., Howes, V., E., (2005) Beyond STS: A Researchbased Framework for Sociocientific Issues Education. Science Education. 89(3), 357-377. 